\title{
Laser Drilling of Epoxy-Glass Printed Circuit Boards
}

\author{
Shozui Takeno ${ }^{*}$, Masaharu Moriyasu ${ }^{* *}$, Masaki Kuzumoto ${ }^{* * *}$, Miki Kurosawa ${ }^{*}$ and Yoshinori Hirata ${ }^{* * *}$ \\ ${ }^{*}$ Nagoya Works,Mitsubishi Electric Corporation, 1-14, Yada-minami 5-chome, Higashi-ku, \\ Nagoya, Aichi 461-8670, Japan \\ E-mail: Takeno.Shozui@aj.MitsubishiElectric.co.jp \\ ${ }^{* *}$ Manufacturing Engineering Center, ${ }^{* * *}$ Advanced Technology R\&D Center, Mitsubishi Electric \\ Corporation, 1-1, Tsukaguchi-honmachi 8-chome, Amagasaki, Hyogo 661-8661, Japan \\ Graduate School of Engineering, Osaka University, 2-1 Yamadaoka, Suita, Osaka 565-0871, Japan
}

\begin{abstract}
The drilling of microvias for epoxy-glass printed wiring boards (PWBs) by $\mathrm{CO}_{2}$ laser radiation was studied experimentally and theoretically. In the experimental approach, the effects of laser pulse duration and frequency on the thickness of the carbonized layer surrounding the drilled holes were investigated for pulse durations of 50-120 $\mu$ s and frequencies of 20-80 Hz. It was found that carbonization takes place at frequencies higher than a certain value and that the frequency becomes lower as the pulse duration increased. Heat accumulation was investigated theoretically in the region near the drilled holes during the removal process. It was reasonably assumed that sudden carbonization takes place when the temperature of the drilled hole surface exceeds the carbonizing temperature of epoxy resin $(\cong 573 \mathrm{~K})$ by the heat accumulation. The analytical study revealed there exists a practically acceptable region of pulse duration and frequency where the temperature of the drilled surface does not reach the carbonizing temperature and no carbonization takes place due to the heat accumulation. Based on the above results, a $\mathrm{CO}_{2}$ laser drilling system was developed to make microvias in epoxy-glass PWBs.

DOI: $10.2961 /$ jlmn.2009.02.0008
\end{abstract}

Keywords: drilling, microvias, epoxy-glass printed wiring boards, $\mathrm{CO}_{2}$ laser, pulse duration, pulse frequency, heat accumulation

\section{Introduction}

Electronic machines for information and communication, such as portable telephones and personal computers are now smaller in size, lighter in weight and more advanced in functions.

This means that the demand for higher circuit density in printed wiring boards (PWBs) has lately increased to the extent that the holes which connect PWB layers, called via holes, have decreased in diameter from $0.3 \mathrm{~mm}$ to $0.1 \mathrm{~mm}$ (These are called microvia holes) [1].

Drilling conventional holes below $0.2 \mathrm{~mm}$ in diameter generally involves a substantial reduction of the drilling rate and is likely to cause breakages of the drill [2], making its application to mass production difficult.

Therefore, the application of the laser such as $\mathrm{CO}_{2}$ laser, ultraviolet $\mathrm{Nd}$ :YAG laser and excimer laser to drilling microvia holes has been considered. In the case of $\mathrm{CO}_{2}$ laser, good quality vias can be drilled in non-reinforced glass laminates $[3,4]$. But in reinforced glass laminates, the protrusions of glass fiber and the carbonization of resin by thermal effects would be a problem in the quality $[3,6]$. In the case of ultraviolet Nd:YAG laser and excimer laser, the quality is no problem [5.6] but drilling speed is low. So productivity and production costs would be a problem for the application to the mass production.

The authors of this paper, therefore, selected $\mathrm{CO}_{2}$ laser drilling as an effective method for mass production, and report a study of the laser irradiation conditions appropriate to epoxy-glass printed circuit boards, the typical PWB materials, in order to optimize the method for both mass production and high quality.
This paper further describes the $\mathrm{CO}_{2}$ laser drilling machine system for PWBs developed on the basis of the results of their study.

\section{Experimental method}

\subsection{Change in thickness of recast layer during drilling due to increase in frequency}

An SD (silent discharge) excitation, 3-axis orthogonal $\mathrm{CO}_{2}$ laser capable of generating a laser beam with a higher peak and shorter pulse than the conventional $\mathrm{CO}_{2}$ laser was used in the experiments [7]. The laser was irradiated onto a $0.5 \mathrm{~mm}$ thick epoxy-glass printed circuit board (FR-4) clad on one side with copper foil (thickness: $18 \mu \mathrm{m}$ ) with a $\phi 530$ $\mu \mathrm{m}$ section removed by etching [8], as shown in Fig. 1, in order to measure the change in the thickness of the recast layer due to an increase in frequency. The recast layer was composed of a carbonized layer turned black by carbonization and a heat affected layer of the same color as the base material.

After drilling, the thickness of the recast layer was obtained by measuring the sum of the residual heat affected layer and the carbonized layer around the hole on the rear surface of the board as shown in Fig. 2. In the experiment, since a perfectly round hole could not be drilled, the mean measured values in a certain orthogonal direction were taken as the recast layer thickness. Five holes were drilled under the same drilling conditions, and their mean values were taken, with the experimental conditions are given in Table 1. 


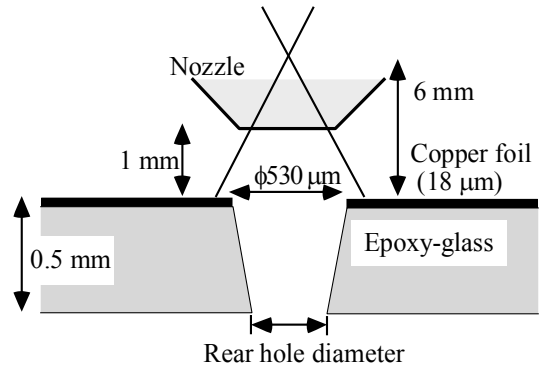

Fig. 1 Drilling method

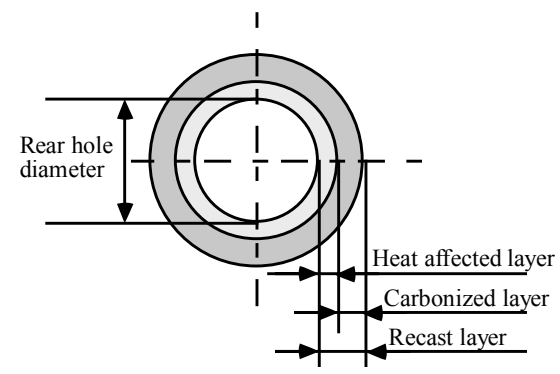

Fig. 2 Method of measuring the recast layer thickness

Table 1 Experimental Conditions

\begin{tabular}{|l|l|}
\hline Pulse duration & $50,120 \mu \mathrm{s}$ \\
\hline Peak output & $2.3,5.6 \mathrm{~kW}$ \\
\hline Input energy & $5.8,11.5,17.4 \mathrm{~J}$ \\
\hline Processing lens & $\mathrm{ZnSe}, 5$ inch \\
\hline Focus position & $6 \mathrm{~mm}$ over focus \\
\hline Nozzle height & $1 \mathrm{~mm}$ from sample surface \\
\hline Nozzle diameter & $3 \mathrm{~mm}$ \\
\hline Assist gas & Oxygen $10 \mathrm{1} / \mathrm{min}$ \\
\hline
\end{tabular}

\subsection{Relation between pulse waveform and drilling rate}

A TEA (traversely excited atmospheric pressure) $\mathrm{CO}_{2}$ laser ( $920 \mathrm{~L}$ by Lumonics, pulse energy: $2 \mathrm{~J} /$ pulse, pulse duration: $1 \mu \mathrm{s}$ ) was used to examine the relation between the acrylic resin (PMMA) removal rate and the energy and power densities. The laser beam from an oscillator outlet of $20 \mathrm{~mm} \times 20 \mathrm{~mm}$ was condensed at a focal length of 95.25 $\mathrm{mm}$ before being irradiated on the PMMA at different focal positions to measure the removal rate by using a profilometer. The beam irradiation area, $\mathrm{S}$, at the irradiation position was measured by using the burn pattern on laser alignment paper (by Kentek), while the energy density of the irradiated beam, F, and the mean power density, $\mathrm{P}$, were obtained by the equations given below.

$$
\begin{aligned}
& \mathrm{F}=\mathrm{E} / \mathrm{S} \\
& \mathrm{P}=\mathrm{F} / \tau
\end{aligned}
$$

where $\mathrm{E}$ is the pulse energy and $\tau$ is the pulse duration.

\section{Experimental results}

\subsection{Change in recast layer thickness due to frequency increase}

The sectional shape of a drilled hole is shown in Fig. 3 when the frequency was changed at $120 \mu \mathrm{s}$ and $5.6 \mathrm{~kW}$. Here, the hole is subjected to plating after drilling to observe the sectional shape more clearly. As is shown in the figure, a carbonized layer is produced on the inner wall of the drilled hole at a frequency of $50 \mathrm{~Hz}$, indicating that the layer is thicker at the rear surface of the hole.
Figure 4 shows the relation between the frequency and the recast layer thickness when the pulse duration and peak output are changed, with the input energy kept at the constant levels of $5.8 \mathrm{~J}, 11.5 \mathrm{~J}$ and $17.4 \mathrm{~J}$. A sharp increase in the recast layer thickness is seen at frequencies around 40 $\mathrm{Hz}$ to $60 \mathrm{~Hz}$. A careful observation of the recast section reveals that, at frequencies below the level causing a sharp increase of the recast layer thickness, the recast layer consisted of only the heat affected layer, with the carbonized layer being generated when the recast layer thickness

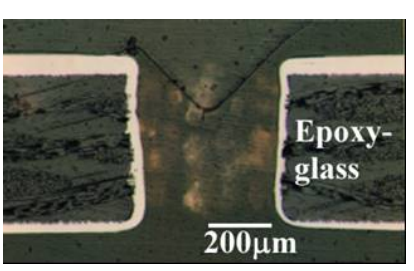

a) $20 \mathrm{~Hz}$

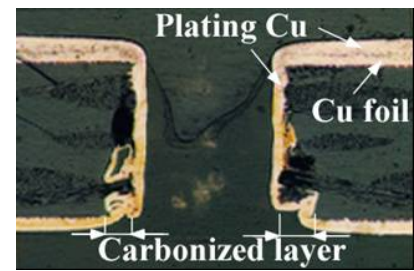

b) $50 \mathrm{~Hz}$
Fig. 3 Change in sectional shape due to change in frequency $(120 \mu \mathrm{s}, 5.6 \mathrm{~kW} \times 50$ pulse $)$

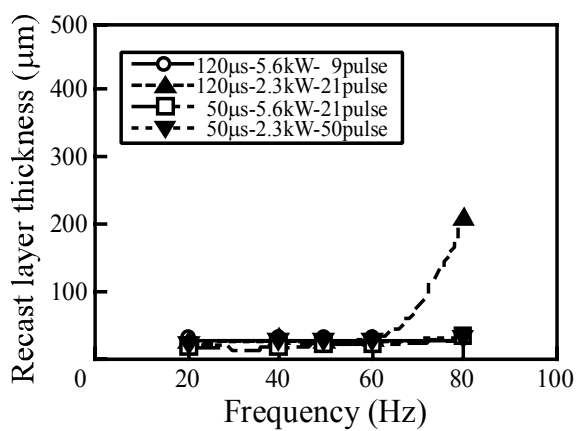

a) Input energy $(5.8 \mathrm{~J})$

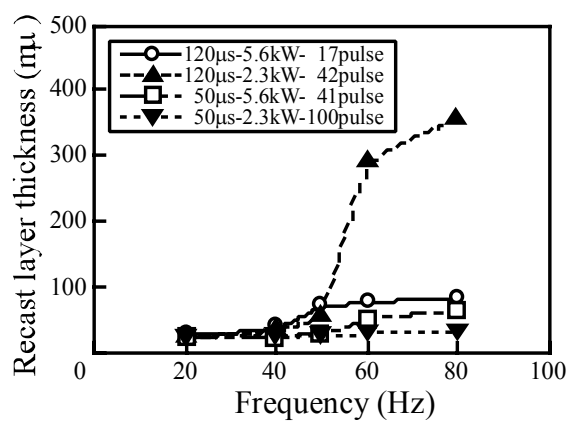

b) Input energy ( $11.5 \mathrm{~J})$

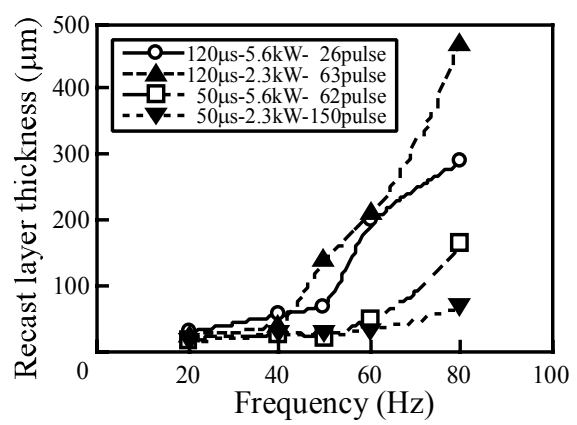

c) Input energy (17.4 J)

Fig. 4 Relation between frequency and recast layer thickness 
shows a sharp increase. It can, therefore, be concluded that the sharp increase of the recast layer thickness implies a sharp increase in the carbonized layer. It was also found that the frequency causing the sharp increase in the carbonized layer is reduced as the input energy is increased.

Here, the recast layer thickness tends to increase due to the increased frequency most conspicuously at $\boldsymbol{\Delta}(120 \mu \mathrm{s}$, $2.3 \mathrm{~kW})$, then at $\circ(120 \mu \mathrm{s}, 5.6 \mathrm{~kW})$, at $\square(50 \mu \mathrm{s}, 5.6 \mathrm{~kW})$, and least conspicuously at $\boldsymbol{\nabla}(50 \mu \mathrm{s}, 2.3 \mathrm{~kW})$.

Further, when the peak level is the same ( $\boldsymbol{\Delta}$ and $\boldsymbol{\nabla}$, 0 and $\square$ ), the recast layer thickness shows little difference at the input energy of $5.8 \mathrm{~J}$ except for a frequency of $80 \mathrm{~Hz}$. The thickness becomes larger as the pulse duration becomes longer at over $40 \mathrm{~Hz}$ when the input energy is increased.

At a constant pulse duration ( $\square$ and $\boldsymbol{\nabla}$, $\circ$ and $\boldsymbol{\Delta}$ ), however, the recast layer thickness shows a smaller increase at $120 \mu \mathrm{s}$ when the peak is high, while at $50 \mu$ s the increase in thickness is less when the peak is low.

On the other hand, with the energy level for one pulse being same ( $\boldsymbol{\Delta}$ and $\square$ ), the recast layer thickness shows less increase when the pulse is shorter and the peak is higher ( $\square$ ).

In other words, the pulse frequency causing the increase in share of the carbonized layer can be increased by using a pulse smaller in duration and higher in peak, allowing the drilling time to be shortened.

\subsection{Relation between pulse waveform and drilling rate}

Figure 5 shows the relation between the PMMA removal rate and the energy density for 1 pulse, observed by using a TEA $\mathrm{CO}_{2}$ laser. The removal depth shows an increase as the energy density increases up to the energy density level of $250 \mathrm{~kJ} / \mathrm{m}^{2}$, but at levels above this the removal depth is inversely reduced, indicating plasma generation in the irradiated section with an impulsive sound.

In laser drilling, when the pulse peak output is larger and the power density higher, an air breakdown phenomenon takes place, causing the atmospheric gas in the beam irradiated section to transform into plasma [9]. The laser energy is absorbed in the plume thus formed by the plasmatic gas before the laser beam reaches the drilling spot, causing the removal rate to decrease.

An air breakdown also seems to have taken place in this experiment at the energy density level above $250 \mathrm{~kJ} / \mathrm{m}^{2}$, with the threshold power density for the occurrence of air breakdown being $250 \mathrm{GW} / \mathrm{m}^{2}$. It is necessary, therefore, to keep the power density for PWB drilling below 250 $\mathrm{GW} / \mathrm{m}^{2}$.

Supposing $\mathrm{F}_{\mathrm{Th}}\left(\mathrm{kJ} / \mathrm{m}^{2}\right)$ to be the required minimum energy density for the removal, the required minimum power density $\mathrm{P}_{\mathrm{Th}}$ at pulse duration $\tau(\mu \mathrm{s})$ is given by:

$$
\mathrm{P}_{\mathrm{Th}}=\mathrm{F}_{\mathrm{Th}} / \tau
$$

It is necessary that $\mathrm{P}_{\mathrm{Th}}<250 \mathrm{GW} / \mathrm{m}^{2}$ to increase the drilling rate, so that

$$
(\mu \mathrm{s})>\mathrm{F}_{\mathrm{Th}} / 250
$$

In the case of epoxy-glass printed circuit boards, it is difficult to remove the glass cloth when the energy density is decreased, causing the glass balls to remain in the drilled section. The energy density in this case differs according to the diameter, density and stitch of the glass fibers, with the average energy density (input energy / hole area) in the experiment being $500 \mathrm{~kJ} / \mathrm{m}^{2}$.

Hence, it is evident from equation (4) that a pulse duration of several $\mu \mathrm{s}$ is needed for effective drilling on an epoxy-glass printed circuit board without a reduction in removal rate occurring due to air breakdown.

In actual drilling, however, the energy density shows a high distribution rate at the center of the hole, so that the maximum energy density is several times higher than the average energy density, and since the pulse waveform is also not completely rectangular, the pulse duration should mandatorily be about $2-10 \mu \mathrm{s}$.

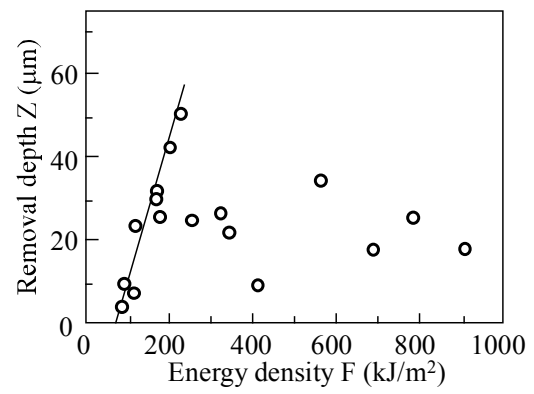

Fig. 5 Relation between removal depth and energy density (PMMA)

\section{Study based on the theory of heat conduction}

In this section a theoretical calculation is worked out using a heat conduction model in order to examine the mechanism of the increased carbonized layer due to increase in frequency, and also the effect of the pulse waveform.

\subsection{Calculation model}

The primary heat conduction model shown in Fig. 6 was used for the analysis. For simplicity's sake the material removal is not taken into consideration here.

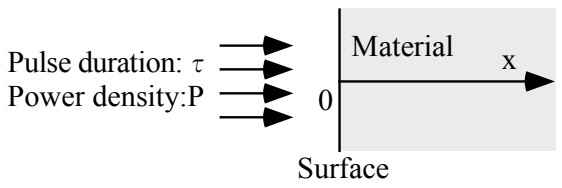

Fig. 6 Model for analysis

When a pulse laser beam of pulse duration $\tau$ and power density $\mathrm{P}$ is irradiated onto the surface of the material, the temperature distribution $\mathrm{T}(\mathrm{x}, \mathrm{t})$ in the direction of the depth at the time $t$ from the laser beam irradiation is given by the equations given below [10].

$$
\begin{aligned}
\text { Beam on; } T(x, t) & =\frac{2 P \sqrt{\kappa t}}{K}\left[\operatorname{ierfc} \frac{x}{2 \sqrt{\kappa t}}\right] \\
\text { Beam off; } T(x, t) & =\frac{2 P \sqrt{\kappa}}{K}\left[\sqrt{t} \operatorname{ierfc} \frac{x}{2 \sqrt{\kappa t}}\right. \\
& \left.-\sqrt{t-\tau} \text { ierfc } \frac{x}{2 \sqrt{\kappa(t-\tau)}}\right]
\end{aligned}
$$

where $\mathrm{K}$ is the thermal conductivity, and $\kappa$ is the thermal diffusivity, 


$$
\begin{aligned}
& \operatorname{ierfc} x=\frac{1}{\sqrt{\pi}} e^{-x^{2}}-x(1-\operatorname{erf} x) \\
& \operatorname{erf} x=\frac{2}{\sqrt{\pi}} \int_{0}^{x} e^{-\xi^{2}} d \xi
\end{aligned}
$$

The values used for calculation are given in Table 2 . When polymeric materials such as epoxy resin, etc. are heated in an oven to raise the temperature gradually, oxygen and hydrogen are dissociated when the temperature reaches the decomposition level, leaving only carbon to cause carbonization. However, when a high energy beam like a laser beam is irradiated, the zone where the beam is applied becomes overheated and the temperature exceeds the decomposition level, causing an explosive dissociation of oxygen and hydrogen in the resin. This causes the residual carbon to be removed due to the evaporative reaction of oxygen and hydrogen, while some part of the carbon is considered to mix with oxygen or hydrogen before turning into gas.

It is obvious, therefore, that the decomposition temperature differs when the temperature rises abruptly as in the case of laser irradiation or when it rises gradually during overheating. Hence, in this study the decomposition temperature in laser drilling is regarded as the "removal temperature," and was determined as $\cong 1073 \mathrm{~K}$, which is higher than the decomposition temperature of $\cong 573 \mathrm{~K}$. This value was estimated through data regarding PMMA which is rich in laser drilling data and whose working characteristics are similar to epoxy resin, since there is almost no data regarding the laser drilling of epoxy resin itself. Table 3 shows the physical properties of PMMA and the energy required for removal at the time of laser drilling. Here, the removal temperature can be calculated as approximately $1073 \mathrm{~K}$ from the Removal energy / (Specific heat x Density) +273 .

Table 2 Physical properties of epoxy resin for calculation

\begin{tabular}{|l|c|}
\hline Thermal conductivity $(\mathrm{W} / \mathrm{mK})$ & 0.18 \\
\hline Thermal diffusivity $\left(\mathrm{m}^{2} / \mathrm{s}\right)$ & $1.43 \times 10^{-7}$ \\
\hline Decomposition temperature $(\mathrm{K})$ & 573 \\
\hline Specific heat $(\mathrm{J} / \mathrm{kgK})$ & 1050 \\
\hline Density $\left(\mathrm{kg} / \mathrm{m}^{3}\right)$ & $1.2 \times 10^{3}$ \\
\hline Removal temperature $(\mathrm{K})$ & $\cong 1073$ \\
\hline
\end{tabular}

Table 3 Physical properties of PMMA [11]

\begin{tabular}{|l|c|}
\hline Thermal conductivity $(\mathrm{W} / \mathrm{mK})$ & 0.17 \\
\hline Thermal diffusivity $\left(\mathrm{m}^{2} / \mathrm{s}\right)$ & $0.42 \times 10^{-7}$ \\
\hline Decomposition temperature $(\mathrm{K})$ & 573 \\
\hline Specific heat $(\mathrm{J} / \mathrm{kgK})$ & 3360 \\
\hline Density $\left(\mathrm{kg} / \mathrm{m}^{3}\right)$ & $1.2 \times 10^{3}$ \\
\hline Removal energy $\left(\mathrm{J} / \mathrm{m}^{3}\right)$ & $3 \times 10^{9}$ \\
\hline
\end{tabular}

\subsection{Effect of pulse frequency}

The inner wall of the hole is removed by laser irradiation during drilling, causing the hole to expand in the radial direction (radial expansion). This reduces the power density of the laser beam irradiated onto the inner wall, so that after the pulse irradiation, the radial expansion of the hole apparently stops at a point where the inner wall surface of the hole has a temperature equivalent to the removal temperature. In this study, the surface temperature is calculated on the basis of this assumption. In other words, the change in surface temperature $(x=0)$ is calculated when a beam of a specified number of pulses is irradiated at a specified frequency after setting the value of $\mathrm{P}$, so that $\mathrm{T}(0, \tau)=$ $1073 \mathrm{~K}$ at pulse duration $\tau$ and when $\mathrm{x}$ in equation (5) is zero.

Figure 7 shows the change in surface temperature of the material when a beam of 50 pulses is irradiated on the epoxy resin, with the pulse duration being $100 \mu \mathrm{s}$. The initial temperature before irradiation obviously shows a gradual rise as the number of pulses increases, exceeding the decomposition temperature of the epoxy resin at $50 \mathrm{~Hz}$. This indicates that at $50 \mathrm{~Hz}$ the carbonized layer is formed on the inner wall of the drilled hole after an irradiation of 50 pulses. This tendency differs slightly according to the drilling conditions, but it conforms to the sectional shape seen in Fig. 3.

Thus, it can be deduced that the sharp increase in the carbonized layer due to the increase in pulse frequency is attributed to the regenerative reaction due to the continuous irradiation of pulses.

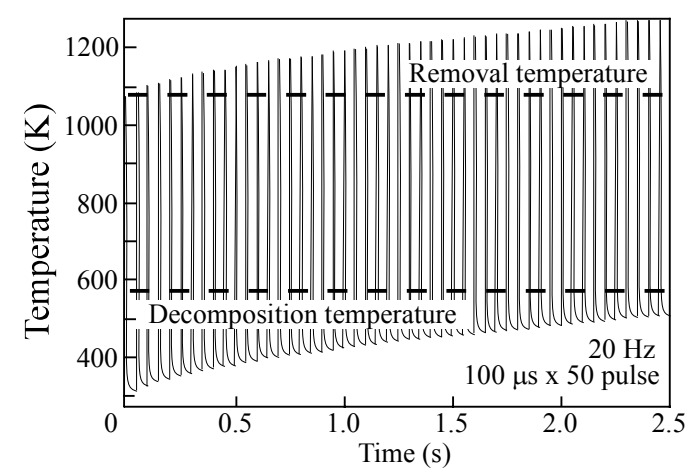

a) Frequency: $20 \mathrm{~Hz}$

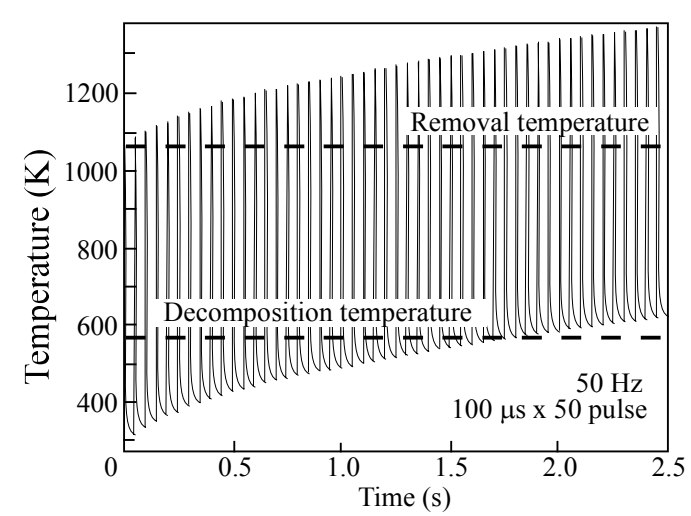

b) Frequency: $50 \mathrm{~Hz}$

Fig. 7 Effect of pulse frequency on surface temperature

\subsection{Effect of pulse waveform}

This section describes the relation between the heat accumulation rate and pulse waveform and the effect of the pulse waveform on the heat affected layer thickness. The effect of the pulse waveform on the heat affected layer thickness is investigated in the following manner. As in the case of the effect of pulse frequency (4.2), the irradiation power density for different pulse durations is calculated to obtain the temperature distribution in the depth direction after irradiation with a pulse of the calculated power density. Here, the difference in depth between the removal temperature and the decomposition temperature of the ep- 
oxy is defined as the heat affected layer thickness in the calculation model to examine the effect of the pulse duration on the heat affected layer.

\subsubsection{Heat accumulation rate}

We will see here the reason why the carbonized layer thickness tends to increase due to the increase in frequency is most conspicuous in $\boldsymbol{\Delta}(120 \mu \mathrm{s}, 2.3 \mathrm{~kW})$, followed by $\bigcirc(120 \mu \mathrm{s}, 5.6 \mathrm{~kW})$ and $\square(50 \mu \mathrm{s}, 5.6 \mathrm{~kW})$, while it is least conspicuous in $\nabla(50 \mu \mathrm{s}, 2.3 \mathrm{~kW})$. The heat accumulation rate causing the carbonized layer to become thicker is expressed as follows.

$$
\text { Heat accumulation rate }=\sum_{n=1}^{N}\left[\mathrm{E}_{1}-\mathrm{E}_{2}-\mathrm{E}_{3}\right]
$$

Where, $E_{1}$ is input energy at nth pulse, $E_{2}$ is energy consumed by removal material at $n$th pulse, $\mathrm{E}_{3}$ is energy not absorbed by material at $n$th pulse and $\mathrm{N}$ is the number of pulses.

Therefore, with the peak constant, $\mathrm{E}_{1}$ increases and $\mathrm{N}$ decreases when the pulse duration becomes larger; while $\mathrm{E}_{1}$ decreases and $\mathrm{N}$ increases when the pulse duration becomes smaller. Thus the heat accumulation rate depends on both the pulse count and the pulse duration, not only on the pulse duration.

Similarly, the heat accumulation rate cannot be determined simply by making the pulse duration constant. The heat accumulation rate (carbonized layer thickness) is found to be reversed for $50 \mu \mathrm{s}$ and $120 \mu \mathrm{s}$.

With the energy for one pulse and the pulse count being the same, $\mathrm{E}_{2}$ increases and the heat accumulation rate decreases when the pulse is short and the peak is high. This tendency conforms well to the experimental results.

Thus, the pulse frequency causing a conspicuous regenerative reaction can be increased by means of a pulse waveform with a short pulse and a high peak.

\subsubsection{Heat affected thickness}

Figure 8 shows the affect of heat on the thickness obtained through calculation by changing the pulse duration, indicating clearly that the thickness of the heat affected layer can be reduced from the conventional $8 \mu \mathrm{m}$ to $2.6 \mu \mathrm{m}$ by shortening the pulse duration of a $\mathrm{CO}_{2}$ laser from the conventional $500 \mu$ s to $50 \mu$ s. The thickness can be further reduced to less than $1 \mu \mathrm{m}$ by reducing the pulse duration to 2 - $10 \mu \mathrm{s}$. It is obvious, therefore, that the heat affected layer thickness can be reduced by shortening the pulse duration of a pulse waveform.

\section{5. $\mathrm{CO}_{2}$ laser drill system for printed wiring boards}

\subsection{Drilling machine}

The configuration of the $\mathrm{CO}_{2}$ laser drill system for PWBs (ML605GTWII-H-5150U), developed on the basis of the above experiments and studies, is shown in Fig. 9. Figure 10 is a photograph of its appearance and its specifications are given in Table 4.

From the experimental data obtained, the pulse duration was set between $1 \mu$ s and $100 \mu$ s taking into consideration quality and productivity.

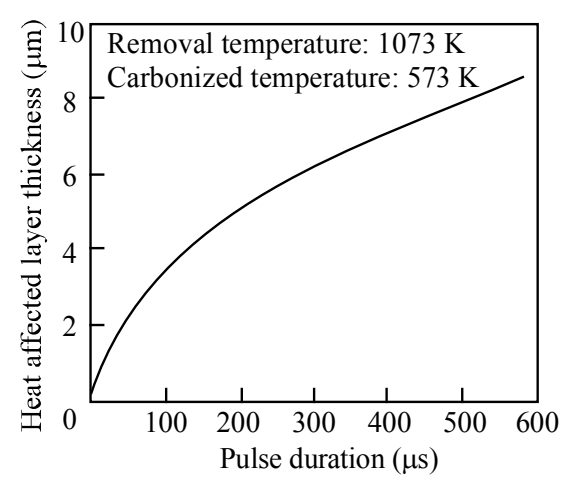

Fig. 8 Effect of pulse duration on heat affected layer

Two PWBs are drilling at once by two laser beams and two tables. Each laser beam is positioned at high speed over a scanning area of $70 \mathrm{~mm} \times 70 \mathrm{~mm}$ on the PWB by means of a revolving galvanomirror and $\mathrm{f}-\theta$ lens in order to drill holes. When the drilling in the scanning area is completed, the PWB is moved by the XY table to the next scanning area to receive laser beam irradiation. This process is repeated until the drilling of the entire PWB is finished.

At the time of drilling in the scanning area, a 1 pulse laser irradiates each hole, and after drilling all the holes in the PWB, the 1 pulse laser irradiation is repeated again for each hole until the specified number of pulses have been irradiated. This minimizes the increase of drilling time inside the scanning area, and provides a sufficient pulse pause time per unit drilled hole, restricting the generation of the carbonized layer on the material due to heat accumulation.

The maximum drilling rate on $1 \mathrm{~mm}$ pitch inside the scanning area is $1700 \times 2$ holes per second. Holes ranging in diameter from a maximum of $400 \mu \mathrm{m}$ to minimum of 45 $\mu \mathrm{m}$ can be drilled by changing the mask diameter of the mask imaging optics.

The vision sensor recognizes the alignment mark on the PWB through image processing to correct positional errors when setting the PWB to the XY table, and errors due to expansion or contraction of the PWB. Each unit in the system is controlled by means of a controller using a PC system controller (PC-NC).

The drilling machine with this configuration ensures a positioning accuracy of $\pm 20 \mu \mathrm{m}$, and a normal drilling rate (per PWB) of several hundred holes per second, though the drilling rate may differ according to the board size and the number of holes.

\subsection{Example of drilling}

Figure 11 shows a sectional photo of a microvia hole $150 \mu \mathrm{m}$ in diameter on epoxy glass (FR-4) with an insulation layer thickness of $100 \mu \mathrm{m}$. Fig. 12 shows a sectional photo of a microvia hole subjected to copper plating after drilling a hole $100 \mu \mathrm{m}$ in diameter on epoxy glass (FR-4) with an insulation layer thickness of $100 \mu \mathrm{m}$, indicating the flat inner surface with less protrusions or lumps of glass fiber on the wall surface of the hole. Figure 13 shows an example of drilling a hole $45 \mu \mathrm{m}$ in diameter on a $30 \mu \mathrm{m}$ thick epoxy resin, indicating the high quality hole with less taper. 


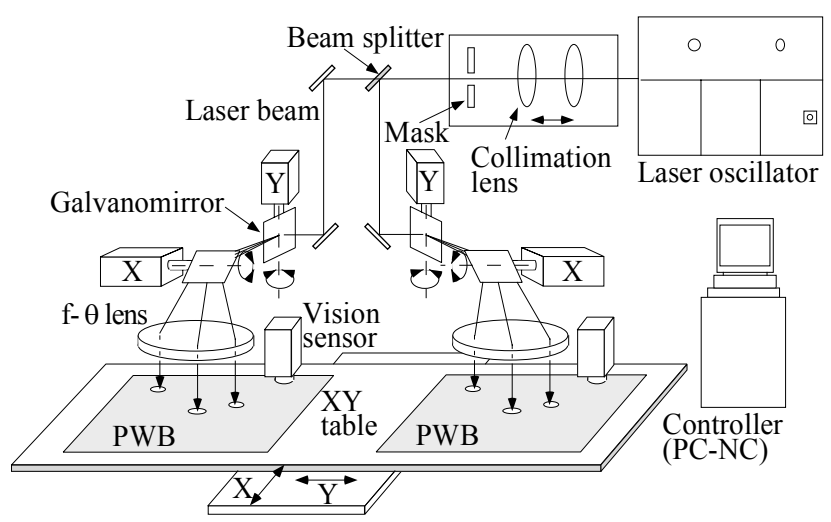

Fig. 9 Configuration of drilling system

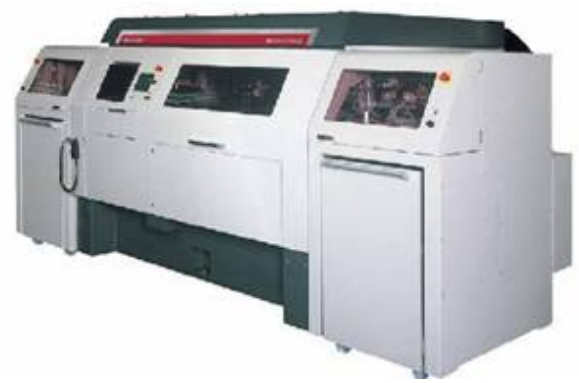

Fig. 10 Appearance of drilling machine

Table 4 Specifications of ML605GTWII-H-5150U

\begin{tabular}{|c|c|c|}
\hline \multirow{2}{*}{\begin{tabular}{|c|} 
Item \\
Galvanometer \\
optical scanner
\end{tabular}} & \multicolumn{2}{|c|}{ Specifications } \\
\hline & $\begin{array}{l}\text { Max. scanning area }(\mathrm{mm}) \\
\text { Positioning speed }(\text { point } / \mathrm{s}) \\
\text { Positioning accuracy }(\mu \mathrm{m}) \\
\text { Repeat accuracy }(\mu \mathrm{m})\end{array}$ & $\begin{array}{l}70 \times 70 \\
1700 \text { (pitch: } 1 \mathrm{~mm}) \\
\pm 20 \\
\pm 15\end{array}$ \\
\hline $\mathrm{XY}$ table & $\begin{array}{l}\text { Drilling stroke }(\mathrm{mm}) \\
\text { Max. feed speed }(\mathrm{m} / \mathrm{min}) \\
\text { Positioning accuracy }(\mathrm{mm}) \\
\text { Repetition accuracy }(\mu \mathrm{m})\end{array}$ & $\begin{array}{l}620 \times 560 \\
50 \\
\text { X-axis: } 0.005 \\
\text { Y-axis: } 0.005 \\
\pm 2\end{array}$ \\
\hline & Z-axis stroke $(\mathrm{mm})$ & 70 \\
\hline Oscillator & $\begin{array}{l}\text { Beam mode } \\
\text { Rated output }(\mathrm{W}) \\
\text { Pulse frequency }(\mathrm{Hz}) \\
\text { Pulse duration }(\mu \mathrm{s}) \\
\end{array}$ & $\begin{array}{l}\text { Single mode } \\
150 \\
10-6200 \\
1-100 \\
\end{array}$ \\
\hline
\end{tabular}

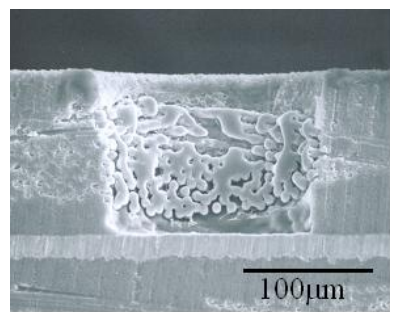

Fig. 11 Cross section SEM photograph of microvia hole on epoxy-glass

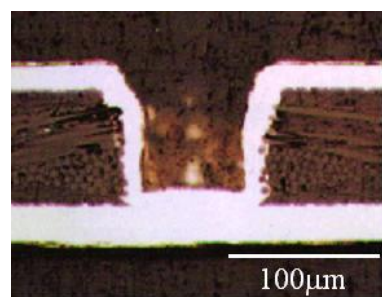

Fig. 12 Cross section photograph of microvia hole on epoxy-glass

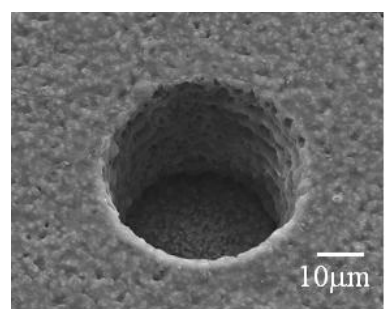

Fig. 13 SEM photograph of microvia hole on epoxy resin

\section{Conclusion}

The experiments and heat conduction analyses of the through hole drilling of epoxy-glass printed wiring boards by using a high-peak, short-pulse $\mathrm{CO}_{2}$ laser have revealed the following points.

1) The carbonized layer thickness is sharply increased around the drilled holes at 40 to $60 \mathrm{~Hz}$ when the pulse frequency is increased.

2) The pulse frequency causing the sharp increase of carbonized layer thickness becomes higher when a pulse waveform with a short pulse and a high peak is used, contributing to the shortening of drilling time.

3) An excessively small pulse duration causes a substantial reduction of the drilling rate due to air breakdown.

4) The sharp increase in the carbonized layer thickness due to the increase of the pulse frequency is attributed to heat accumulation around the drilled region.

5) According to the simple heat conduction model, the thickness of the heat affected layer can be reduced from 8 $\mu \mathrm{m}$ to $2.6 \mu \mathrm{m}$ by decreasing the pulse duration from $500 \mu \mathrm{s}$ to $50 \mu \mathrm{s}$, and further to less than $1 \mu \mathrm{m}$ by decreasing the pulse duration to $2 \mu \mathrm{s}-10 \mu \mathrm{s}$. On the basis of this data, a new $\mathrm{CO}_{2}$ laser drill system has been developed for printed wiring boards to allow high-quality drilling at the maximum drilling rate of $1700 \times 2$ holes per second.

\section{References}

[1] Y. Tsukada, S. Tsuchida and Y. Mashimoto: Proc. 42nd ECTC (1992) p.22.

[2] A.L. Kenney III and J.W. Dally: Circuit World, Vol.14 No.3 (1988) p.31.

[3] J.M. Morrison, T.G. Tessier and B. Gu: Circuit World, Vol.21 No.1 (1994) p.24.

[4] L.W. Burgess and G.E. Jones: Proc. Tech. Program National Electronic Packaging Prod. Conf. (1992) p.1773.

[5] M. Owen, E. Roelants and J.V. Puymbroeck: Circuit World, Vol.24 No.1 (1997) p.45.

[6] F. Bachmann: MRS Bulletin, December (1989) p.49.

[7] S. Takeno, M. Moriyasu, S. Hiramoto: Proc.of the ICALEO'92, 75 (1992) p.459.

[8] M.N. Watson: The Welding Institute Reserch Bulletin September (1984) p.289.

[9] D.E. Lencioni: Appl. Phys. Lett., 23-1 (1973) p.12.

[10] H.S. Carslaw and J.C. Jaeger: Conduction of heat in solids, 2nd ed. Oxford at the Clarendon Press. (1959) p.75.

[11] I. Miyamoto: Proc. of the ICALEO'84, 44 (1984) p.313.

(Received: May 21, 2009, Accepted: July 10, 2009) 